Notas Clínicas

\title{
Carcinoma de células en anillo de sello extramamario tras cáncer de mama: ¿cuándo se trata realmente de un segundo primario?
}

A. S. Rubiales, T. Álvarez Gago ${ }^{1}$, P. Rey ${ }^{2}$, M. L. del Valle, E. Uña, L. Gómez²

\section{Resumen}

- Propósito: Es frecuente que los cánceres de mama presenten áreas de diferenciación celular en anillo de sello. Además, este subtipo celular puede estar presente en las metástasis y no aparecer en el tumor primario.

- Material y métodos: Presentamos dos pacientes tratadas por cáncer de mama que desarrollaron tumores con células en anillo de sello, gástrico y endocervical respectivamente, que fueron considerados inicialmente como segundos tumores primarios.

- Resultados: En ambos casos, el estudio inmunohistoquímico encontró receptores hormonales en las células en anillo de sello, lo que orientó al diagnóstico de metástasis de cáncer de mama.

- Conclusiones: El cáncer de mama puede desarrollar metástasis con células en anillo de sello. La presencia de receptores hormonales en estas células tiene una especificad cercana al 100\% en el diagnóstico diferencial entre metástasis de cáncer de mama y tumor de origen digestivo.

\section{Palabras clave:}

Carcinoma de mama. Células en anillo de sello. Receptores hormonales.

Oncología, 2005; 28 (9):448-452

Servicios de Oncología y Anatomía Patológica.

${ }^{1}$ Hospital Clínico Universitario. Valladolid

${ }^{2}$ Servicio de Radioterapia. Hospital Virgen de la Concha. Zamora 


\section{Summary}

- Purpose: The majority of breast cancers show areas of signet-ring cell differentiation. In addition, this cellular subtype may be present in the metastases even when it does not appear in the primary tumour.

- Material and methods: We report two patients treated for breast cancer developing signet-ring cell tumours of gastric and endocervical localization, respectively, that were initially considered as second primary tumours.

- Results: In both cases, the immunohistochemical analysis of the signet-ring cells proved to be positive for hormone receptors, confirming them as breast cancer metastases.

- Conclusions: Ductal and lobular breast cancer may produce distant metastases with signet-ring cells. The presence of specific hormone receptors reaches almost $100 \%$ and represents a reliable differential diagnosis between breast cancer metastases and gastrointestinal signet-ring cell carcinomas.

Key words: Breast cancer. Signet.ring cells. Hormone receptors.

\section{Introducción}

En 1976 se caracterizó el cáncer de mama de células en anillo de sello ${ }^{1}$. El porcentaje de tumores que entran en este subgrupo es escaso ${ }^{2}$, probablemente cercana al $1 \%$ de todos los cánceres de mama $^{3}$. Se caracterizan por presentar una proporción especialmente elevada de células en anillo de sello celular y se consideran, salvo en casos excepcionales ${ }^{4}$, como un subtipo de carcinoma lobulillar. Sin embargo, son numerosas las series que describe que la mayoría de los cánceres de mama, tanto ductales como lobulillares, presentan áreas de diferenciación celular en anillo de sello ${ }^{5-7}$. Estos tumores no entran dentro de la definición específica del cáncer de mama de células en anillo de sello pero es probable que compartan parte de las características de este subtipo celular. De hecho, se ha descrito que la presencia de células en anillo de sello se asocia a una historia natural peculiar, tal vez más agresiva, y con mayor tendencia a desarrollar metástasis gastrointestinales y ginecológicas.

Es posible que las células en anillo de sello se manifiesten únicamente en las metástasis y no en el tumor primario, algo que puede ocasionar dudas diagnósticas. Presentamos los casos de dos pacientes en que la recidiva de su neoplasia de mama fue diagnosticada inicialmente como un segundo tumor primario de células en anillo de sello en una localización compatible (estómago, cuello uterino) de modo que sólo la sospecha clínica y el estudio de la presencia de receptores hormonales mediante técnicas de inmunohistoquímica permitieron confirmar que se trataba de metástasis de su cáncer de mama.

\section{Pacientes}

\section{Paciente 1}

En 1995, a los 40 años, se le practicó mastectomía con disección axilar en otra ciudad. El informe histológico fue de carcinoma lobulillar infiltrante. El diámetro máximo del tumor primario era $3 \mathrm{~cm}$ (T2). De la axila se aislaron 14 ganglios, 4 de ellos infiltrados por el tumor; no fue posible acceder a más datos sobre los receptores hormonales. Tras la intervención recibió quimioterapia complementaria con seis ciclos de FEC.

En 2000 comenzó a padecer dolor en epigastrio acompañado de una pérdida de peso superior a 10 Kg. En Noviembre de 2000 se encontró, mediante gastroscopia, una masa de aspecto tumoral en el cuerpo gástrico. La biopsia fue informada como adenocarcinoma difuso con células en anillo de sello (Fig. 1). En enero del año 2001 se practicó una laparotomía en la que se encontró ascitis y una neoplasia gástrica irresecable que atravesaba la pared del estómago e infiltraba la cabeza del páncreas. La citología de líquido ascítico fue compatible con invasión por células en anillo de sello. Inició entonces tratamiento citostático con quimioterapia. En Diciembre 


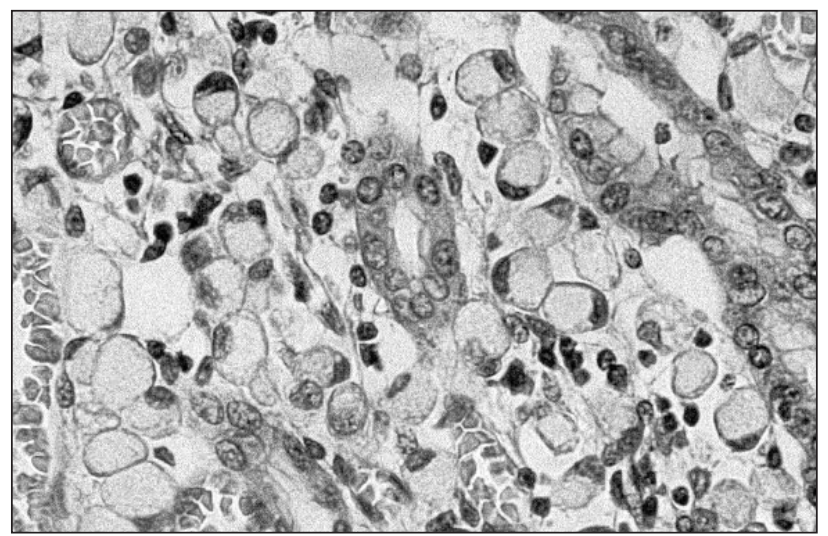

Figura 1. Biopsia gástrica de la Paciente 1. Adenocarcinoma difuso con células en anillo de sello.

de 2001 comenzó con dolor dorsal; en la gammagrafía ósea se encontraron captaciones múltiples compatibles con metástasis óseas que se confirmaron mediante resonancia magnética. Desde entonces ha sido tratada con radioterapia antiálgica y ha recibido asimismo diversas líneas de quimioterapia y de tratamiento hormonal que mantiene en la actualidad. La supervivencia prolongada de la paciente animó a ampliar los estudios de la biopsia gástrica que permitieron confirmar la presencia de receptores de estrógeno y de progesterona en las células en anillo de sello (Fig. 2).

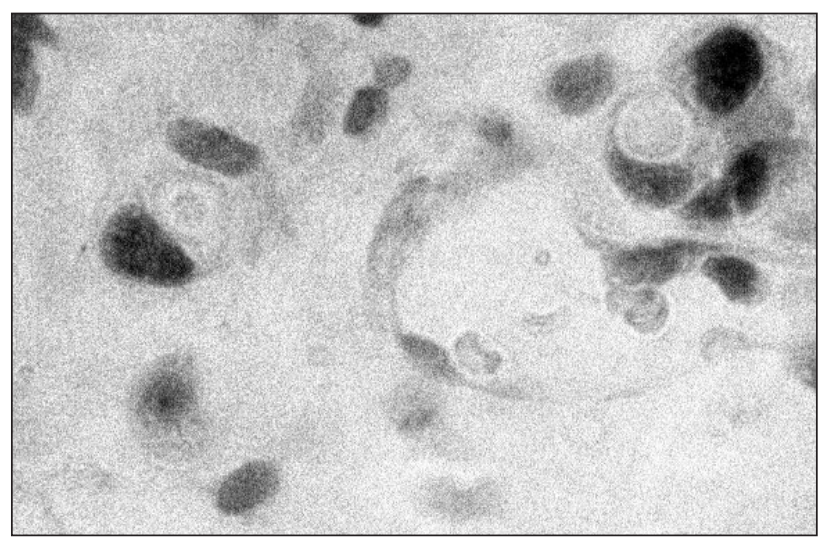

Figura 2. Biopsia gástrica de la Paciente 1. Estudio inmunohistoquímico que muestra la presencia de receptores de estrógeno en las células en anillo de sello.

\section{Paciente 2}

En 1999, a los 66 años, se le practicó mastectomía con disección axilar izquierda. El diagnóstico histológico fue de carcinoma ductal infiltrante moderada- mente diferenciado, de $1,5 \mathrm{~cm}$ de tamaño (T1c). Se aislaron 8 ganglios, 3 afectados por la enfermedad. Los receptores de estrógenos y de progesterona eran positivos. Se le administró quimioterapia complementaria (seis ciclos de CMF) y, posteriormente, radioterapia y tratamiento hormonal con tamoxifeno.

En los últimos meses de 2004 comenzó a referir metrorragias en cantidad escasa. En Enero de 2005 se añadieron dolores óseos. La biopsia tomada mediante histeroscopia fue informada como adenocarcinoma mucinoso pobremente diferenciado con células en anillo de sello, compatible con tumor primario de cérvix. Los estudios de extensión mostraron afectación metastásica ósea y hepática. Si bien inicialmente se planteó como un segundo tumor primario de origen endocervical, los datos clínicos y la presencia simultánea de afectación ósea y hepática recomendaron una reevaluación de la histología. En los estudios inmunohistoquímicos se encontró positividad para receptores de estrógeno y de progesterona en la pieza de biopsia endocervical, lo que llevó a interpretar todo el cuadro como diseminación a distancia de su cáncer de mama. En la actualidad recibe tratamiento paliativo con quimioterapia.

\section{Comentario}

El diagnóstico previo de cáncer de mama se asocia a un riesgo de padecer segundos tumores primarios discretamente superior al de la población normal. Sin embargo, este riesgo parece limitarse a un subgrupo de tumores, principalmente neoplasias de tipo ginecológico, en las que puede encontrarse un factor genético común, y a los sarcomas, probablemente inducidos en algunos casos por los tratamientos (radioterapia...) que reciben estas pacientes ${ }^{8}$. En los tumores digestivos, sólo la incidencia del carcinoma de vesícula biliar es significativamente superior a la de la población normal.

Los cánceres de mama pueden metastatizar en cualquier órgano. No obstante, parece que existe un cierto proceso de selección, de origen aún por definir, que produce por una parte que las metástasis intraabdominales por cáncer de mama suelan provenir de tumores de tipo lobulillar y con receptores hormonales positivos ${ }^{9}$ y que las neoplasias de mama que presentan células en anillo de sello tiendan a desarrollar metástasis por una parte en el útero, tan- 
to en el cérvix como en el endometrio ${ }^{10-15}$, y por otra en el peritoneo y el tracto gastrointestinal ${ }^{16}$, especialmente en el estómago ${ }^{17-21}$.

No es frecuente que la diseminación metastásica de un cáncer de mama requiera un diagnóstico diferencial de un segundo tumor primario. Sin embargo, las neoplasias con células en anillo de sello tanto en el cérvix ${ }^{22}$ como, sobre todo, en el aparato digestivo, principalmente en el estómago ${ }^{23}$, se suelen interpretar como tumores primarios de esas localizaciones. Esto ha provocado en más ocasiones errores en el diagnóstico en enfermas que habían padecido previamente un cáncer de mama ${ }^{17,20}$. Esto es algo que es fácil de comprender cuando, como sucede en nuestras pacientes, tanto el modo de presentación clínica como la histología orientan a un segundo tumor, especialmente cuando en el informe anatomopatológico del cáncer de mama no consta la presencia de células en anillo de sello. Y el riesgo de confusión aumenta si coincide la circunstancia de que el diagnóstico clínico y anatomopatológico se lleva a cabo en Centros diferentes de manera que no es posible disponer de toda la información previa.

En todo caso, una vez que se conoce que la paciente ya había sido diagnosticada de cáncer mama, es conveniente recordar que cualquier afectación tumoral por células en anillo de sello puede ser manifestación de diseminación metastásica de este tumor, independientemente del tipo de histología del tumor primario (ductal o lobulillar) o de que presentase o no células en anillo de sello. Es posible, incluso, que en las metástasis del cáncer de mama aparezca una diferenciación en anillo de sello que no se encontraba en las células del tumor primario ${ }^{15,24}$.

En general, en el diagnóstico diferencial del origen mamario o digestivo de los carcinomas y sus metástasis se propone el estudio de las citoqueratinas $^{2,25}$, CK-7 y CK-20, y del GCDFP-15 (gross cystic disease fluid protein $)^{15,26}$ junto con el de los receptores hormonales. Sin embargo, cuando este diagnóstico diferencial se ciñe a tumores con células en anillo de sello con afectación abdominal ${ }^{27}$, el estudio aislado de receptores hormonales alcanza una sensibilidad superior al $80 \%$ y una especificidad que en algunos estudios alcanza el $100 \%$ ya que en estos trabajos no se encontraron receptores hormonales en ninguno de los tumores digestivos con diferenciación en anillo de sello ${ }^{3,25,28}$. Esta característica llama la atención ya que la desdiferenciación que supone la presencia de células en anillo de sello en las metástasis de cáncer de mama no se asocia a una pérdida de la expresión de los receptores hormonales.

En resumen y como criterio práctico, es conveniente mantener una actitud de sospecha en los casos en que se diagnostican segundos tumores primarios con células en anillo de sello en enfermas que han padecido previamente un cáncer de mama ya que es probable que estos tumores correspondan a diseminación metastásica del cáncer de mama. En todo caso, si se trata de un tumor digestivo y las células en anillo de sello presentan receptores hormonales, lo prudente sería asumir que se trata de metástasis de su primario de mama. Sólo si el estudio de receptores hormonales fuera negativo sería razonable ampliar las técnicas inmunohistoquímicas con el estudio de CK-7, CK-20 y GCDFP-15.

Correspondencia:
Dr. A. S. Rubiales
Oncología Médica
Hospital Clínico Universitario
C/ Ramón y Cajal, 3
E-47005 Valladolid
E-mail: asrubiales@ @otmail.com

\section{Bibliografía}

1. Steinbrecher JS, Silverberg SG. Signet-ring cell carcinoma of the breast. The mucinous variant of infiltrating lobular carcinoma? Cancer 1976; 37: 828-40.

2. Jiménez Martín J, Hierro Martín I, Sánchez del Charco M, Espadas Padial B. Carcinoma de células en anillo de sello primario de mama. Diagnóstico diferencial inmunohistoquímico. Rev Senol Patol Mam 2003, 16: 70-4.

3. Eltorky M, Hall JC, Osborne PT, el Zeky F. Signet-ring cell variant of invasive lobular carcinoma of the breast. A clinicopathologic study of 11 cases. Arch Pathol Lab Med 1994; 118: 245-8.

4. Liu SM, Chen DR. Signet-ring cell carcinoma of the breast. Pathol Int 2000; 50: 67-70.

5. Sethi S, Cajulis RS, Gokaslan ST, Frias-Hidvegi D, Yu $\mathrm{GH}$. Diagnostic significance of signet ring cells in fine-needle aspirates of the breast. Diagn Cytopathol 1997; 16: 117-21.

6. Greeley CF, Frost AR. Cytologic features of ductal and lobular carcinoma in fine needle aspirates of the breast. Acta Cytol 1997; 41: 333-40. 
7. Sturgis CD, Sethi S, Cajulis RS, Hidvegi DF, Yu GH. Diagnostic significance of benign pairs and signet ring cells in fine needle aspirates (FNAs) of the breast. Cytopathology 1998; 9: 308-19.

8. Levi F, Te VC, Randimbison L, La Vecchia C. Cancer risk in women with previous breast cancer. Ann Oncol 2003; 14: $71-3$.

9. Abboud B, Sayegh R, Chahine G, et al. Métastases gastriques du cancer du sein. Presse Med 1994; 23: 1758-9.

10. Piura B, Bar-David J, Goldstein J. Abnormal uterine bleeding as a presenting sign of metastatic signet ring cell carcinoma originating in the breast. Case report. $\mathrm{Br} \mathrm{J}$ Obstet Gynaecol 1985; 92: 645-8.

11. Fiorella RM, Beckwith LG, Miller LK, Kragel PJ. Metastatic signet ring carcinoma of the breast as a source of positive cervicovaginal cytology. A case report. Acta Cytol 1993; 37: 948-52.

12. Kennebeck $\mathrm{CH}$, Alagoz T. Signet ring breast carcinoma metastases limited to the endometrium and cervix. Gynecol Oncol 1998; 71: 461-4.

13. Pambuccian SE, Bachowski GJ, Twiggs LB. Signet ring cell lobular carcinoma of the breast presenting in a cervicovaginal smear. A case report. Acta Cytol 2000; 44: 824-30.

14. Chehal A, Seoud M, Taher A, Salem N, Khalil A, Shamsseddine A. Endometrial metastasis from signet-ring breast carcinoma: case report. Eur J Gynaecol Oncol 2002 ;23: 563-4.

15. Acikalin MF, Oner U, Tekin B, Yavuz E, Cengiz O. Metastasis from breast carcinoma to a tamoxifen-related endometrial polyp. Gynecol Oncol 2005; 97: 946-8.

16. Merino MJ, Livolsi VA. Signet ring carcinoma of the female breast: a clinicopathologic analysis of 24 cases. Cancer 1981; 48: 1830-7.

17. Kondo Y, Akita T, Sugano I, Isono K. Signet ring cell carcinoma of the breast. Acta Pathol Jpn 1984; 34: 875-80.
18. Park $\mathrm{CH}$, Whang HS, Park HB. Bilateral signet-ring cell carcinoma of the breast: scintigraphic findings. Clin Nucl Med 1996; 21: 115-7.

19. Yim H, Jin YM, Shim C, Park HB. Gastric metastasis of mammary signet ring cell carcinoma. JKMS 1997; 12: 25661.

20. Furuno K, Asaga T, Uchiyama M, et al. Orbital and stomach metastasis from invasive lobular breast carcinoma. Nippon Ganka Gakkai Zasshi 1998; 102 :135-41.

21. Warmerdam FA, Blaauwgeers JL, de Valk B, Roozendaal $\mathrm{KJ}$. A gastric signet ring cell carcinoma as the first expression of a breast carcinoma. Ned Tijdschr Geneeskd 2003; 147: 980-4.

22. Moll UM, Chumas JC, Mann WJ, Patsner B. Primary signet ring cell carcinoma of the uterine cervix. N Y State J Med 1990; 90: 559-60.

23. Hohenberger P, Gretschel S. Gastric cancer. Lancet 2003; 362: 305-15.

24. Raju U, Ma CK, Shaw A. Signet ring variant of lobular carcinoma of the breast: a clinicopathologic and immunohistochemical study. Mod Pathol 1993; 6: 516-20.

25. Tot T. The role of cytokeratins 20 and 7 and estrogen receptor analysis in separation of metastatic lobular carcinoma of the breast and metastatic signet ring cell carcinoma of the gastrointestinal tract. APMIS 2000; 108: 467-72.

26. Di Cosimo S, Ferretti G, Fazio N, et al. Breast and ovarian metastatic localization of signet-ring cell gastric carcinoma. Ann Oncol 2003; 14: 803-4.

27. Kaufmann O, Deidesheimer T, Muehlenberg M, Deicke P, Dietel M. Immunohistochemical differentiation of metastatic breast carcinomas from metastatic adenocarcinomas of other common primary sites. Histopathology 1996; 29: 233-40.

28. Chu PG, Weiss LM. Immunohistochemical characterization of signet-ring cell carcinomas of the stomach, breast, and colon. Am J Clin Pathol 2004; 121: 884-92. 